Code Feature Section

\title{
CONFINED COLUMNS
}

$$
\text { O. A. Glogau * }
$$

Why confined columns in building frames designed for beam hinging mechanisms?

Modern aseismic codes call for confinement of concrete in columns of ductile moment resisting space frames. A further requirement of these codes is that the ultimate moment capacity of the columns at the design earthquake axial load should exceed that of the beams framing into it. The purpose of the latter of these provisions is to prevent the formation of column hinge mechanisms. Park (New Zealand Engineering, November 1968) has shown that even for low buildings the formation of a column hinge in a lower storey will result in very high local ductility demands, dangerous to confined columns and certainly disasterous to unconfined columns. This view is reflected in the current M.O.W. Code of Practice which allows column hinge mechanisms only in buildings less than 3 storeys high having low axial stress and fully confined columns.

Requirements such as these are not easily met in pract:ce, particularly in medium height buildings, where the architecture frequently calls for deep spandrels and slender columns. The ultimate strength of such sprandrels even when having only minimum reinforcement ratios is difficult to match by the columns. The conscious engineer who, having with some difficulty persuaded the architect to change his concept, has finally achieved a ductile moment resisting frame designed to form beam hinges is dismayed and often puzzled why he should still confine the concrete in the columns. The writer, pondering the same problem, has convinced himself that the present state of the art requires a second line if defence in the majority of cases. Listed below are a number of reasons why, notwithstanding our design precautions, unforeseen column hinges and overcapacity loadings on columns may eventuate :

\section{Possible sources of increased ultimate beam capacity relative to columns}

\section{(a) Variations in Yield point of rein- forcing bars}

In this country and apparently also in the U.S.A. reinforcing steel has a guaranteed minimum yield point only, e.g. the New Zealand H.Y. 40 bar may have a yield point as high as $50 \mathrm{ksi}$. The yield point of A.S.T.M. - grade 60 bars is reported to fluctuate between 60 and $90 \mathrm{ksi}$. Most designs are based on mimimum yield strength and this assumption alone may lead to under estimation of ultimate beam strength by 25 to 50 per cent.

\section{(b) Strain hardening}

This is a further possible source of unforeseen increased beam strength in the case of large excursions into the

\footnotetext{
* Chief Structural Engineer, Ministry of Works.
}

yield range. The use of einforcing steel with a large yielc strain plateau (e.g. New Zealand H.Y.40) minimumises this danger.

\section{(c) Concrete strength}

The ultimate capacity of a column may be significantly reduced by low concrete strength. Beam flexural strength is not greatly influenced by variations in concrete strength.

\section{Slab reinforcing}

The extent by which slab reinforcing contributes to the ultimate strength of a beam - column junction is uncertain. In medium height buildings with large slab spans parallel to the framing beams under consideration, slab reinforcing may result in a significant increase in negative support moment capacity of beams.

2. Additional unforeseen column stresses due to conventional design approaches or lack of design data

(a) Tortional effects due to beam eccentricity (refer Mead, volume 3, No. 1 of this Bulletin).

(b) Bi-axial moment effects on the beam columns junctions

The stresses in this zone resulting from the concentrated forces of the yielding beam reinforcing are in themselves uncertain. The complexity is increased when we consider the combined effect of beam reinforcing reaching yield stresses in one principal direction and the simultaneous application of a moment applied by a beam framing at $90^{\circ}$ into the junction. This effect is particularly severe at exterior columns, where the greatest redistributions are required.

(c) Higher stresses in corner columns particularly in "squarish" buildings with few columns resulting from a "diagonal earthquake" rather than the

application of an earthquake in a principal direction.

(d) Uncertainties due to the dual purpose of hoop reinforciny in beam column junctions as shear reinforcing and confining steel. Tests to aate have not clearly separated stress produced in the hoop reinforcing due to anchorage of yielding beam reinforcing and confinement of concrete.

(e) Current code provisions are based on tests carried out on relatively small members . 